\title{
Terapia comunitária: \\ prática relatada pelos profissionais da rede SUS de Santa Catarina, Brasil
}

Cristina dos Santos Padilha ${ }^{1}$

Walter Ferreira de Oliveira ${ }^{2}$

PADILHA, C.S.; OLIVEIRA, W.F. Community therapy: practice reported by professionals within SUS in Santa Catarina, Brazil. Interface - Comunic., Saude, Educ., v.16, n.43, p.1069-83, out./dez. 2012.

The aim of this exploratory and descriptive study was to describe the community therapy practices reported by 27 healthcare professionals within the Brazilian National Health System (SUS), in Santa Catarina, Brazil. The data were gathered through individual semidirected interviews, and content analysis was used for categorical themes. The results were grouped into five categories: community therapy practices; implementation strategies; difficulties; facilitative elements; and benefits. It was concluded that community therapy can contribute towards construction of expanded clinical action and improved value for territory resources. However, community therapists' actions need to be extended to a multidisciplinary team, have dialogue with other entities, receive support from service management and be allied to other public policies, in order to expand their field of action from healthcare to other sectors.

Keywords: Community therapy. SUS. Healthcare professionals. Healthcare practices. Psychosocial intervention.
O objetivo deste estudo, de natureza exploratória e descritiva, foi descrever as práticas de Terapia Comunitária relatadas por 27 profissionais de saúde da rede do Sistema Único de Saúde (SUS) de Santa Catarina, sul do Brasil. Os dados foram coletados por meio de entrevistas individuais semidirigidas, empregando-se a Análise de Conteúdo como temática categorial. Os resultados foram agrupados em cinco categorias: práticas de terapia comunitária; estratégias de implantação; dificuldades; elementos facilitadores; e benefícios. Conclui-se que a Terapia Comunitária pode contribuir para a construção de uma clínica ampliada e para a valorização dos recursos do território. No entanto, é necessário que a atuação do terapeuta comunitário seja estendida a uma equipe multidisciplinar, dialogue com outros dispositivos, receba o apoio das gestões dos serviços e se alie a outras políticas públicas, ampliando seu campo de ação da saúde para outros setores.

Palavras-chave: Terapia comunitária. SUS. Profissionais de saúde. Práticas de saúde. Intervenção psicossocial.
${ }^{1}$ Departamento de Psicologia, Universidade do Oeste de Santa Catarina. Rua Clevelândia, $32 \mathrm{D}$, apto. 703, Centro. Chapecó, SC, Brasil. 89.802-410 padilha.psico@gmail.com

${ }^{2}$ Departamento de Saúde Coletiva, Universidade Federal de Santa Catarina 


\section{Introdução}

A Terapia Comunitária (TC), desenvolvida pelo Departamento de Saúde Comunitária da Faculdade de Medicina da Universidade Federal do Ceará e sistematizada desde 1987, é definida como uma metodologia de intervenção em comunidades, por meio de encontros interpessoais e intercomunitários. Seu objetivo é a promoção da saúde através: da construção de vínculos solidários, valorização das experiências de vida dos participantes, do resgate da identidade, da restauração da autoestima e ampliação da percepção dos problemas e possibilidades de resolução a partir das competências locais (Andrade et al., 2009).

Esse instrumento se propõe a auxiliar a construção de redes solidárias e tem como alicerce cinco eixos teóricos: Pensamento Sistêmico, Teoria da Comunicação, Antropologia Cultural, Pedagogia de Paulo Freire e conceito de Resiliência. Esses enfoques teóricos legitimam algumas premissas e posturas adotadas pelos terapeutas comunitários, tal como o reconhecimento da importância de perceber o sujeito em seu contexto, como parte indissociável de uma rede de relações. As trocas intersubjetivas são mediadas pela linguagem, daí a necessidade de se contextualizar culturalmente as diversas palavras e significados, valorizando conhecimentos, crenças e manifestações populares imprescindíveis para a transformação do indivíduo em sujeito agente de sua própria história. As experiências de vida e o conhecimento delas advindo devem ser partilhados de forma horizontal e circular. Acredita-se que indivíduos e grupos sociais dispõem de mecanismos próprios para superar as adversidades contextuais (Camargo, 2005).

A aprovação da Política Nacional de Práticas Integrativas e Complementares (PNPIC) em 2006 dá subsídios para estender a TC - prática que já acontece há mais de vinte anos em Fortaleza - a outras regiões do país. Em 2008, é firmado um convênio entre o Ministério da Saúde (MS) e a Fundação Cearense de Pesquisa e Cultura para implantar a TC na Rede de Assistência à Saúde do Sistema Único de Saúde (SUS). O projeto visa desenvolver, nos profissionais de saúde e nas lideranças comunitárias, as competências necessárias para lidar com os sofrimentos e demandas psicossociais e promover redes de apoio social, ampliando a resolutividade da Atenção Básica (Brasil, 2006c).

A inserção da TC no SUS responde às demandas expressas na Política Nacional de Atenção Básica, entre elas: a implementação das diretrizes da Política Nacional de Humanização (PNH) através do acolhimento, da realização da escuta qualificada das necessidades dos usuários e do estabelecimento do vínculo (Brasil, 2008; 2006a). Responde, também, aos interesses da Política Nacional de Promoção da Saúde, que tem como uma de suas diretrizes fortalecer a participação social, entendendo-a como fundamental na consecução de resultados de promoção da saúde, em especial, a equidade e o empoderamento individual e comunitário, privilegiando as práticas de saúde sensíveis à realidade do Brasil (Brasil, 2006b).

Em Santa Catarina, em 2009, foram selecionados profissionais de saúde para a realização de um curso de formação em TC, financiado pelo MS e pela Secretaria de Saúde do Estado. A relevância de tal proposta ancora-se na visão de que são necessários novos sujeitos com tecnologias apropriadas para encontrar respostas satisfatórias construídas coletivamente. A necessidade de se implantar um modelo de atenção à saúde mental com base comunitária, priorizando-se a promoção da saúde e a prevenção do adoecimento, coincide com a proposta da TC de criar redes de apoio solidárias a indivíduos e famílias que vivenciam situação de sofrimento emocional ou psíquico. O presente trabalho resgata essa experiência de capacitação e objetiva descrever as práticas de TC relatadas pelos profissionais de saúde da rede SUS de Santa Catarina.

\section{Práticas de TC no contexto da saúde coletiva}

As pesquisas sobre a TC no contexto da saúde coletiva têm se voltado para as repercussões desse instrumento na vida do usuário. Alguns estudos abordam a realidade da Atenção Básica, nos grupos específicos de TC ou nos grupos temáticos que ocorrem nas unidades de saúde, como grupos com gestantes ou idosos, e que incorporam essa metodologia (Andrade et al., 2010; Filha et al., 2009; Guimarães, Vala, 2009; Rocha et al., 2009; Souza et al., 2007; Victor et al., 2007; Guimarães, 2006; 
Holanda, 2006). Outros estudos se voltam para o contexto dos Centros de Atenção Psicossocial (CAPS), indicando a TC como um instrumento capaz de fomentar a construção da rede e explorar os recursos do território (Filha, Carvalho, 2010; Mota, 2007; Machado, 2006). Alguns autores discorrem ainda sobre a necessidade de capacitação dos profissionais da Estratégia Saúde da Família (ESF) para a promoção de um atendimento integral, o que requer lidar, também, com as demandas de saúde mental, apontando a TC como um instrumento que pode responder parcialmente a essa demanda profissional (Silva, 2010; Soares, 2008; Fukui, Machetti, 2004).

A TC praticada no âmbito do SUS traz inovações às práticas grupais: importa mais a experiência de vida das pessoas do que o saber técnico, todos detêm conhecimento, sem hierarquizações das relações interpessoais, sendo desejável que as pessoas compartilhem sentimentos. Nesse espaço, a identidade do terapeuta comunitário prevalece sobre a identidade do profissional de saúde, essa é a essência da proposta que pretende fortalecer vínculos e humanizar as relações entre a comunidade e os profissionais.

Tal forma de atuar é congruente com a proposta da clínica ampliada e com o enfoque transdisciplinar em saúde. De acordo com Campos (2005), a clínica ampliada, uma das diretrizes da PNH (Brasil, 2008), requer que o profissional construa vínculos duradouros com os usuários e se aproxime das redes familiares e sociais dos mesmos. Através da elucidação dos aspectos orgânicos, subjetivos e sociais de cada sujeito, é possível respeitar a singularidade de cada caso. O enfoque transdisciplinar (Lopes, 2009), por sua vez, faz dialogar diversas formas de saber e vários níveis de realidade, trazendo importantes contribuições para a prática clínica, já que, filosoficamente, todo membro da equipe é considerado um parceiro de igual para igual, e suas habilidades profissionais, qualidades pessoais, valores, tradições culturais, emoções, conhecimento, treino e experiências de vida são atributos valiosos para o funcionamento do grupo, incluindo o doente.

O acolhimento, uma das diretrizes da PNH, é percebido, por Tesser, Poli Neto e Campos (2010), como uma proposta para a melhoria das relações dos serviços de saúde com os usuários, concretizado no encontro do usuário que procura o serviço espontaneamente com profissionais de saúde e caracterizado pela escuta, processamento da demanda e busca de resolução. Essas formas de atenção à demanda espontânea propõem-se a servir de elo entre as necessidades dos usuários e as várias possibilidades de cuidado. A ideia é retirar do médico o papel de único protagonista do cuidado, ampliar a clínica realizada pelos outros profissionais e incluir outras abordagens e explicações, além das biomédicas, para os adoecimentos e demandas. Daí a necessidade de se ampliar a oferta de serviços e de cuidados, sendo desejável a oferta e invenção de rituais de encontro, espaços terapêuticos individuais e coletivos, o que requer estímulo institucional e um processo de educação permanente e capacitação clínica para os profissionais. O acolhimento pode chegar a auxiliar a desmedicalização quando, além da habilidade clínica, houver: trabalho conjunto em equipe, construção de projetos terapêuticos e avaliações de riscos/vulnerabilidades individuais e coletivas, e consideração de elementos da vida familiar e social, para uma abordagem ampliada dos problemas.

Gomes e Merhy (2011), através de revisão de artigos sobre Educação Popular em Saúde e discorrendo sobre as redes de apoio social no território, afirmam que a TC pode integrar ações de prevenção e promoção à saúde que tomam como foco o sujeito, e não as doenças. No entanto, os autores defendem que tais práticas não podem ser desenvolvidas de forma desarticulada de outros modos de luta social, para evitar que seu resultado seja mera resignação ou culpabilização dos sujeitos.

Por isso, o terapeuta comunitário deve: reforçar vínculos entre as pessoas, mobilizar recursos e competências locais, respeitar as distintas culturas, promover redes de proteção e inclusão, e favorecer a conscientização social. Articular atividades dentro da comunidade e entre esta e a rede mais ampla auxilia não só a divulgação da TC, mas a resolução de problemas e a realização de encaminhamentos necessários. A criação de uma equipe de trabalho comunitário pode auxiliar nas articulações necessárias, sendo o trabalho orientado para o incremento da autonomia de indivíduos, grupos e redes (Luisi, 2006).

Somente essas articulações intersetoriais do terapeuta comunitário são capazes de proporcionar o empoderamento psicológico e comunitário. Segundo Carvalho (2004), o empoderamento psicológico é um sentimento de maior controle sobre a própria vida que os indivíduos experimentam através do pertencimento a distintos grupos, e que pode ocorrer sem que as pessoas participem de ações políticas 
coletivas. Já o empoderamento comunitário (Carvalho, Gastaldo, 2008) demanda novos modos de fazer saúde, nos quais os usuários sejam percebidos na sua singularidade de sujeitos portadores de direito, implicando o enfrentamento das causas da iniquidade social, a legitimação de grupos marginalizados e a remoção de barreiras que limitam a produção de uma vida saudável para distintos grupos sociais.

O empoderamento comunitário é um enfoque congruente ao de promoção da saúde tal como enunciado por Buss (2003), para quem, inicialmente, a promoção caracteriza um nível de atenção da medicina preventiva e evolui para um enfoque político e técnico em torno do processo saúde-doençacuidado. Tal enfoque está associado a valores como: vida, saúde, solidariedade, equidade (distribuição de renda e acesso a bens e serviços), democracia, cidadania, desenvolvimento, participação e parceria, sendo complementar ao enfoque da prevenção. A promoção da saúde identifica e enfrenta os macrodeterminantes do processo de saúde-doença e busca transformá-los na direção da saúde, tendo como objetivo contínuo um nível ótimo de saúde. Para tanto, fazem-se necessários: o protagonismo de indivíduos não técnicos e de movimentos sociais, ações combinadas de políticas públicas, modificações de estilos de vida e intervenção ambiental. Saúde é sinônimo de bem-estar e qualidade de vida, estado dinâmico socialmente produzido.

O pensamento de Paulo Freire é um dos eixos teóricos da TC e a base da Educação Popular, caracterizada por Vasconcelos (2004) como um saber importante para a construção da participação popular, servindo não apenas para a criação de uma nova consciência sanitária, como, também, para uma democratização mais radical das políticas públicas. Não é apenas um estilo de comunicação e ensino, mas, também, um instrumento de gestão participativa de ação social. É, ainda, o jeito brasileiro de fazer promoção da saúde. O autor ressalta a importância de que a Educação Popular deixe de ser uma prática social que acontece de forma pontual no SUS, por meio da luta heroica de alguns profissionais e de movimentos sociais, para ser generalizada amplamente nos diversos serviços de saúde. Uma das estratégias apontadas para isto é o apoio a iniciativas de formação profissional que busquem reorientar as atitudes dos trabalhadores de saúde na relação com a população, de forma a problematizar vivências, compartilhar iniciativas de enfrentamento e busca de soluções, e valorizar a curiosidade na busca de entendimento das raízes das questões sociais mais importantes.

Na visão de Albuquerque e Stotz (2004), apesar de a educação popular se destacar dentre as formas alternativas de educação em saúde, podendo constituir-se um instrumento auxiliar na incorporação de novas práticas por profissionais e serviços de saúde, no dia a dia pouca ou nenhuma importância é dada às ações educativas. Trabalhos em grupos são, muitas vezes, marginalizados, profissionais envolvidos desacreditados e desestimulados, a infraestrutura escassa e de difícil acesso. São grandes as dificuldades das equipes de saúde para efetivarem uma prática cotidiana de promoção através de ações educativas. Quando isso acontece, dá-se, muitas vezes, de acordo com o interesse individual dos profissionais, dificilmente estimulando a autonomia e a conscientização das comunidades. Os relatos de experiências de educação popular em saúde nos serviços frequentemente referem-se à "falta de apoio" das coordenações ou das secretarias municipais e estaduais, refletindo o sentimento dos profissionais de estarem solitários no desenvolvimento deste trabalho.

A educação para a saúde tem enfrentado grandes desafios criados pelas suas próprias e contraditórias proposições, em que assumem lugar de destaque: a promoção da livre escolha e, simultaneamente, do ditar de escolhas saudáveis; a necessidade de compatibilizar a livre escolha com as opções ditadas pela medicina; a promoção da autonomia; o advogar de determinadas racionalidades, e a aceitação de escolhas individuais, mesmo se não forem compatíveis com uma vida saudável. A maioria das ações de educação para a saúde continua centrada na prevenção de doenças e na responsabilização individual, não considerando as causas sociais da falta de saúde com a ênfase desejada. As práticas de educação para a saúde têm privilegiado a informação, assumindo ser possível modificar o comportamento individual pela comunicação de mensagens e através de múltiplas estratégias de argumentação, onde se acentuam os efeitos nocivos sobre a saúde, se contrapõem estilos de vida mais saudáveis, se apela à responsabilidade social do portador de determinado risco (Mendes, 2009). 


\section{Método}

Este estudo caracterizou-se como exploratório e descritivo. Participaram 27 profissionais de saúde, capacitados em um curso de Terapia Comunitária, oferecido pela Secretaria de Estado da Saúde de Santa Catarina, em parceria com o MS. Realizado entre 2009 e 2010, o curso disponibilizou 35 vagas e priorizou capacitar trabalhadores da saúde e da assistência social da região do Vale do Itajaí, devido às enchentes e desastres ambientais ocorridos em 2008. O critério de inclusão dos sujeitos nesse estudo foi atuação profissional em serviços vinculados às Secretarias de Saúde dos municípios contemplados com o curso. Dos 28 profissionais que foram contatados, apenas um recusou-se em participar do estudo.

Para a coleta de dados, foram realizadas entrevistas individuais semidirigidas, gravadas e, posteriormente, transcritas. As questões do roteiro, pelo fato de suscitarem um discurso direto e simples, permitiram uma análise por categorias, desmembrando o texto em unidades temáticas. Tomando como referência o trabalho de Bardin (1977), a análise de conteúdo temática categorial seguiu três etapas: Pré-análise; Exploração do material textual; Tratamento dos resultados, inferência e interpretação. A sistematização dos resultados foi pautada por procedimentos propostos por Oliveira (2008) e está expressa no Quadro 1.

\section{Resultados e discussão}

\section{Caracterização dos participantes}

Participaram deste estudo 27 profissionais de saúde da rede SUS de Santa Catarina, dos quais 17 (62,97\% ) são da região do Vale do Itajaí, das cidades de Apiúna, Blumenau, Gaspar, Indaial, Itajaí, Rodeio e Timbó. Dez (37,03\%) profissionais são da região do Litoral, das cidades de Florianópolis e Palhoça.

Dentre os participantes, 20 (74,07\%) são do sexo feminino e sete $(25,93 \%)$ do sexo masculino, a maioria na faixa etária de trinta e 39 anos ( $12-44,44 \%$ ), seguidos por participantes com idade entre vinte e 29 anos ( $7-25,93 \%$ ), entre quarenta e 49 anos (5 - 18,52\%), sendo somente três $(11,11 \%)$ participantes pertencentes à faixa etária de cinquenta a 59 anos.

Em relação à renda familiar, $15(55,56 \%)$ profissionais enquadram-se na categoria que compreende entre cinco e dez salários-mínimos, seis $(22,22 \%)$ têm renda familiar até cinco salários-mínimos, e seis $(22,22 \%)$ têm renda familiar superior a dez salários-mínimos.

A maioria dos sujeitos tem especialização latu sensu (17 - 62,96\%), seguidos por profissionais com curso Superior completo ( $9-33,33 \%)$, e por um (3,71\%) profissional com curso técnico.

Em relação aos cargos ocupados, a maioria atua em equipes técnicas $(21-77,78 \%)$ e o restante na gestão (4 - 14, 81\%) e em coordenações de serviços (2 - 7,41\%). A maioria dos profissionais tem experiência no cargo entre um e cinco anos (15 - 55,56\%), seguidos por profissionais com experiência entre seis e dez anos (6-22,22\%), com experiência menor que um ano (4-14,81\%) e superior a dez anos $(2-7,41 \%)$.

Dentre os serviços a que estão vinculados, encontram-se serviços da Atenção Primária, onde atuam dez $(37,04 \%)$ sujeitos, serviços da Atenção Secundária (basicamente os CAPS), onde atuam 13 $(48,15 \%)$ entrevistados, e instituições de gestão dos serviços de saúde, onde atuam quatro $(14,81 \%)$ profissionais.

\section{TC praticada na rede SUS de Santa Catarina}

A partir da Análise de Conteúdo temática categorial (Bardin, 1977), foram obtidos 29 temas, compostos de trezentas e dez unidades de registro, que se agruparam em cinco categorias: Práticas de TC, Estratégias de Implantação, Dificuldades, Elementos Facilitadores e Benefícios. A seguir, serão detalhados os conteúdos de cada categoria, bem como alguns aspectos relevantes emergentes no processo de categorização do conteúdo. 
Quadro 1. Demonstrativo do processo de construção das categorias temáticas - operacionalização proposta por Oliveira (2008)

\begin{tabular}{|c|c|c|c|c|c|c|}
\hline Cód. & Temas/unidades de significação & Total UR & Total entrev. & Categoria & Total UR & $\%$ \\
\hline 01 & Grupos na atenção básica & 17 & 13 & \multirow{5}{*}{ Práticas de TC } & \multirow{5}{*}{48} & \multirow{5}{*}{15,48} \\
\hline 02 & Grupos no caps & 14 & 13 & & & \\
\hline 03 & Aplicação de preceitos da tc a outras práticas & 07 & 07 & & & \\
\hline 04 & Grupos na comunidade & 05 & 05 & & & \\
\hline 05 & Grupos com profissionais de saúde & 05 & 05 & & & \\
\hline 06 & Realização de grupos com profissionais do serviço & 05 & 05 & \multirow{5}{*}{$\begin{array}{l}\text { Estratégias de } \\
\text { implantação }\end{array}$} & \multirow{5}{*}{16} & \multirow{5}{*}{5,16} \\
\hline 07 & Auxílio dos ACS para divulgação & 05 & 05 & & & \\
\hline 08 & Elaboração de projeto para a gestão local & 03 & 03 & & & \\
\hline 09 & $\begin{array}{l}\text { Capacitação de ACS para atuarem como } \\
\text { coterapeutas }\end{array}$ & 02 & 02 & & & \\
\hline 10 & Divulgação através de cartazes & 01 & 01 & & & \\
\hline 11 & Resistência dos usuários a trabalhos grupais & 22 & 10 & \multirow{7}{*}{ Dificuldades } & \multirow{7}{*}{80} & \multirow{7}{*}{25,81} \\
\hline 12 & Sobrecarga de trabalho & 18 & 11 & & & \\
\hline 13 & Decorrentes do formato metodológico & 17 & 12 & & & \\
\hline 14 & Decorrentes da estrutura e do processo de trabalho & 09 & 09 & & & \\
\hline 15 & Falta de apoio da gestão local & 08 & 04 & & & \\
\hline 16 & Falta de apoio dos demais profissionais do serviço & 03 & 03 & & & \\
\hline 17 & Problemas pessoais & 03 & 03 & & & \\
\hline 18 & $\begin{array}{l}\text { Receptividade dos usuários e demais profissionais } \\
\text { do serviço }\end{array}$ & 05 & 05 & \multirow{4}{*}{$\begin{array}{l}\text { Elementos } \\
\text { facilitadores }\end{array}$} & \multirow{4}{*}{11} & \multirow{4}{*}{3,55} \\
\hline 19 & Vinculação prévia dos usuários ao serviço & 04 & 04 & & & \\
\hline 20 & $\begin{array}{l}\text { Presença de profissional que auxilie a condução } \\
\text { do grupo }\end{array}$ & 01 & 01 & & & \\
\hline 21 & Apoio da gestão local & 01 & 01 & & & \\
\hline 22 & Efeito terapêutico & 38 & 22 & \multirow{9}{*}{ Benefícios } & \multirow{9}{*}{155} & \multirow{9}{*}{50,00} \\
\hline 23 & Fomento das práticas grupais & 28 & 18 & & & \\
\hline 24 & Atenção às demandas de saúde mental & 25 & 18 & & & \\
\hline 25 & Fomento às redes sociais & 21 & 17 & & & \\
\hline 26 & Acolhimento & 12 & 11 & & & \\
\hline 27 & Autonomia & 09 & 07 & & & \\
\hline 28 & Atenção humanizada & 09 & 08 & & & \\
\hline 29 & Congruência com a realidade do SUS & 07 & 07 & & & \\
\hline 30 & Empoderamento & 06 & 05 & & & \\
\hline
\end{tabular}




\section{Práticas de TC}

Essa categoria contém $48(15,48 \%)$ unidades de registro, agrupadas em cinco temas que expressam os diferentes usos que os profissionais relataram ter dado à TC a partir de sua realidade concreta de trabalho, englobando práticas decorridas (27 grupos) e práticas perpetuadas até o momento da coleta de dados (vinte grupos).

A TC é predominantemente aplicada no contexto da Atenção Básica, sendo também utilizada nos CAPS, em grupos específicos ou aplicando seu formato metodológico a outros grupos temáticos oferecidos nos serviços.

Outro uso que os profissionais relatam fazer dessa metodologia é aplicar algum de seus preceitos a outras práticas por eles desenvolvidas. Nesse caso, a TC não é realizada tal como proposto pela formação, com todas as suas etapas e regras, mas alguns aprendizados que os profissionais consideram relevantes passam a ser norteadores de outras práticas desenvolvidas no âmbito da saúde coletiva, como o preceito da horizontalidade:

"Na verdade, a seqüência eu não utilizo, mas tiro bastante coisas da TC para passar para eles (usuários). Tudo o que eu aprendi no grupo, da simplicidade, de estar junto com eles, de não achar que é profissional e que está acima, então eu procuro sempre olhar por esse lado. Eu já vinha tentando fazer isso, mas a TC me ensinou a mostrar para eles esse lado, que para mim é muito importante, mais importante do que qualquer outra teoria". (Sujeito 01)

Os profissionais de saúde utilizam a TC também nas comunidades, desvinculando esses grupos da estrutura física dos serviços de saúde. Esse uso está mais atrelado à proposta de Adalberto Barreto, de valorização do contexto comunitário e, embora considerado desejável pelos profissionais, exige outro nível de articulação com o território e demanda o deslocamento dos serviços onde atuam, o que, na prática, dificilmente ocorre.

Tal resultado evidencia que os profissionais de saúde encontram obstáculos para fazerem articulações com as comunidades e para que a TC possa integrar aquilo que Gomes e Merhy (2011) consideram como ações de prevenção e promoção à saúde articuladas com outros modos de luta social.

Foi também relatada a realização de grupos de TC com profissionais de saúde, como um espaço destinado ao cuidado dos cuidadores. O cuidado do cuidador é um dos módulos da capacitação em TC, bastante valorizado pelos profissionais entrevistados, que se sentiram cuidados. É possível que, a partir dessa capacitação, os profissionais de saúde tenham se sensibilizado para a necessidade de cuidar dos demais profissionais da rede, como uma forma de valorização profissional.

\section{Estratégias de implantação}

Essa categoria contém $16(5,16 \%)$ unidades de registro, agrupadas em cinco temas relativos aos procedimentos adotados pelos sujeitos com a finalidade de efetivar a prática da TC em seu cotidiano de trabalho.

Dentre as estratégias utilizadas, foram relatadas: realização de grupos com profissionais dos serviços, para que conhecessem a proposta e pudessem divulgá-la para os usuários ou, até mesmo, para que pudessem fazer encaminhamentos para esse espaço coletivo; auxílio dos Agentes

Comunitários de Saúde (ACS's), para divulgarem o grupo nas áreas de abrangência dos serviços; elaboração de um projeto para a gestão local, para formalizar a nova proposta e obter autorização para aplicá-la; capacitação de ACS's para atuarem como coterapeutas, e divulgação através de panfletos e cartazes.

Tais estratégias de implantação restringiram-se ao setor saúde, pois, como já relatado, os sujeitos encontram dificuldades para fazerem articulações com instituições comunitárias e movimentos sociais. Os profissionais que têm mais condições para realizar essa articulação, por conta das práticas diárias de visitas domiciliares, são os ACS's, daí a importância de capacitar essa categoria para a condução de trabalhos grupais. 


\section{Dificuldades}

Essa categoria contém oitenta $(25,81 \%)$ unidades de registro, agrupadas em sete temas que classificam as dificuldades percebidas pelos profissionais de saúde para inserir a TC na rede SUS de Santa Catarina.

Um dos temas presentes nessa categoria é a resistência dos usuários a trabalhos grupais, característica atribuída à predominância de um modelo biomédico que se reflete na expectativa por atendimento individual. E, num grupo que se propõe a acolher sofrimentos e dificuldades, tal expectativa faz-se ainda mais notável já que os usuários têm receio de expor suas fragilidades e vulnerabilidades no contexto coletivo, diante de pessoas conhecidas. Além disso, a proposta da TC é nova, ainda pouco difundida, e esse desconhecimento a nível social traz prejuízos para a adesão dos usuários.

Conforme os profissionais relatam, parece ainda não haver uma cultura de grupo entre os usuários e seus familiares, o que corrobora a dificuldade de adesão aos encontros de TC, apontada por Filha e Carvalho (2010). Para tal impasse, pode-se buscar respaldo na reflexão que realiza Mendes (2009) a respeito da preponderância de modelos de educação em saúde caracterizados por relações grupais hierarquizadas e centrados na prevenção de doenças e na responsabilização individual, sem considerar as causas sociais de saúde com a ênfase desejada.

É preciso apontar, também, a necessidade de se avaliarem os usuários previamente ao encaminhamento aos grupos de TC, de forma que os critérios do encaminhamento não se restrinjam à oferta de tal atividade grupal e visem, prioritariamente, os benefícios advindos de tais encontros. Além disso, tal avaliação prévia garante certa vinculação entre usuário e profissional de saúde, potencializando a adesão ao grupo.

A sobrecarga de trabalho é outro fator apontado como dificuldade, já que a TC precisa ser agregada às várias demandas profissionais, o que nem sempre é possível. Como existem poucos terapeutas comunitários capacitados, muitas vezes, não existe auxílio para planejar e executar as dinâmicas dos grupos, sobretudo quando desvinculados dos serviços de saúde, em instituições da comunidade.

Foram relatadas dificuldades decorrentes do formato metodológico da TC, pois algumas padronizações em relação à sua condução não responderam às demandas de contextos grupais específicos. Em determinados contextos, os usuários não conseguem seguir as regras do grupo, têm dificuldades com sua proposta mais lúdica ou têm dificuldades para entender o papel do profissional de saúde quando ocupa o lugar de terapeuta comunitário, conforme evidencia a seguinte passagem:

\footnotetext{
"Por mais que o terapeuta e o co-terapeuta ficassem mais livres, como mediadores mesmo, que é o que a proposta traz, algumas pessoas colocaram que queriam ir para lá para ouvir mais, queriam saber mais da gente já que estavam acompanhadas de duas profissionais. Aquilo ficou tão marcado, porque a gente discutia tanto essa questão de sair do lugar, e a gente tentou tanto sair desse lugar para depois ouvir do usuário 'eu estou aqui com duas profissionais e vocês não trazem nada a mais do que eu já sei? Eu não quero ouvir os meus vizinhos, eu queria saber mais sobre a depressão, sobre os transtornos de ansiedade'. Eles queriam o saber técnico e não o saber popular, por mais que a gente explicasse a proposta". (Sujeito 10)
}

Os profissionais revelam sentimentos de frustração decorrentes da falta de corresponsabilização dos usuários pelos processos de saúde-doença, o que caracteriza uma postura de pouco envolvimento na busca de resoluções dos problemas. Nesse emaranhando de expectativas, os profissionais parecem acreditar que a corresponsabilização dos usuários é o elemento que irá efetivar os objetivos das práticas de saúde; e, por outro lado, os usuários esperam dos profissionais soluções para seus problemas, estando o setor saúde praticamente desarticulado das demais esferas e instituições sociais. Aqui vale resgatar as premissas da promoção da saúde propostas por Buss (2003), cujo objetivo seria o enfrentamento dos macrodeterminantes do processo saúde-doença e a busca contínua de um nível ótimo de saúde, entendida como um estado dinâmico e socialmente produzido. Para tanto, se fazem 
necessários: a ação intersetorial, o protagonismo de indivíduos não técnicos e de movimentos sociais, ações combinadas de políticas públicas, modificações de estilos de vida e intervenção ambiental.

Também geraram dificuldades fatores classificados como decorrentes da estrutura e do processo de trabalho dos profissionais. A falta de espaços apropriados para trabalhos grupais nos serviços, contraditoriamente às demandas da saúde coletiva, constitui um fator que dificulta e, em alguns casos, inviabiliza a realização da TC. Outras situações decorrentes do processo de trabalho, tais como férias e mudança de serviço dos profissionais, interrompem provisória ou definitivamente os grupos, prejudicando a vinculação entre os usuários e destes com os profissionais que são referência naquele contexto grupal. Esse tema inclui, ainda, a resolução do Conselho Federal de Assistência Social (CFESS 569, de 25 de março de 2010) que dispõe sobre a vedação da realização de terapias associadas ao título e/ou ao exercício profissional do assistente social.

A falta de apoio da gestão local também dificulta a prática da TC pelos profissionais de saúde. A difusão dessa prática integrativa de cuidado requer investimentos em novas capacitações e incentivos para que os profissionais capacitados possam fazer um trabalho que não se limite aos serviços onde atuam, envolvendo e integrando as comunidades de forma mais ampla. Finalmente, a falta de apoio dos demais profissionais do serviço, atribuída ao desconhecimento dessa tecnologia de cuidado, e problemas pessoais são também apontados como obstáculos para a efetivação dessa nova proposta.

As dificuldades relatadas corroboram a desvalorização das ações educativas no cotidiano dos serviços, elucidada por Albuquerque e Stotz (2004), segundo os quais se evidencia: na marginalização do trabalho grupal, na falta de estímulo aos profissionais envolvidos, na ausência de infraestrutura adequada, e na falta de apoio das secretarias municipais e estaduais de saúde. As práticas de promoção através de ações educativas são, assim, delegadas ao interesse individual daqueles que persistem e que sozinhos, dificilmente, conseguem estimular a autonomia e a conscientização das comunidades.

\section{Elementos facilitadores}

Essa categoria contém apenas 11 (3,55\%) unidades de registro, agrupadas em quatro temas que expressam os fatores que auxiliaram a inserção da TC no contexto da saúde coletiva.

Dentre os temas apresentados, encontram-se: receptividade dos usuários e demais profissionais do serviço; vinculação prévia dos usuários ao serviço; presença de um profissional que auxilie a condução do grupo, e apoio da gestão local.

\section{Benefícios}

Essa categoria contém 155 (50,00\%) unidades de registro, agrupadas em dez temas relativos aos benefícios proporcionados pela TC na percepção dos profissionais de saúde.

O benefício mais frequente na análise das entrevistas é o efeito terapêutico dos grupos, proporcionado pela configuração de um espaço para a expressão da fala e dos sentimentos e para a troca de experiências, com ênfase nas estratégias de enfrentamento relatadas. Os profissionais percebem que esse espaço coletivo proporciona qualidade de vida para seus integrantes.

De acordo com Guimarães e Valla (2009), essa metodologia favorece a troca de estratégias de enfrentamento dos problemas e fortalece as redes de apoio familiar e social. Além disso, a legitimação do conhecimento produzido a partir das experiências de vida possibilita o empoderamento dos participantes.

A TC também contribui para o fomento das práticas grupais, otimizando vínculos entre os usuários e desses com os terapeutas comunitários, o que reflete positivamente nas dinâmicas e reforça a importância do trabalho com grupos para os demais profissionais dos serviços. Os profissionais capacitados a consideram uma metodologia de fácil aplicação, uma ferramenta de trabalho que proporciona segurança para a condução de grupos e que pode ser ajustada de acordo com a experiência de quem está conduzindo e de acordo com as peculiaridades dos diversos coletivos. As inovações que fazem parte desse novo formato grupal, com destaque para o apelo ao lúdico, são também percebidas como um incentivo à participação dos usuários, essencialmente porque a TC é um espaço inclusivo que 
não restringe a participação de ninguém, como expressa um dos entrevistados: "ah, não é só para gestante, não é só para hipertenso, e sim ter essa riqueza de possibilidade foi muito legal" (Sujeito 04).

Tendo como um de seus eixos teóricos o pensamento de Paulo Freire e pautada pelo preceito de horizontalidade das relações grupais, a TC pode contribuir para aquilo que Vasconcelos (2004) considera a redefinição da prática médica, através da valorização dos saberes e práticas dos sujeitos, usualmente desconsiderados devido à sua origem popular.

Essa metodologia de trabalho com grupos possibilita aos profissionais problematizarem vivências, compartilharem iniciativas de enfrentamento e buscarem entendimento das raízes das questões sociais. Essa atuação diferenciada se aproxima do enfoque transdisciplinar elucidado por Lopes (2009), em que, além das habilidades profissionais, são valorizadas qualidades pessoais, valores, tradições culturais, emoções, conhecimentos, treino e experiência de vida, como atributos valiosos para o funcionamento do grupo.

Outro benefício da TC é a atenção às demandas de saúde mental sem que lhes seja imposto um viés medicalizante. Esse espaço de escuta e de ajuda mútua é por si só resolutivo para algumas demandas, prevenindo que se cronifiquem, além de facilitar o encaminhamento de demandas que necessitam de atenção especializada. Os profissionais relatam sentir mais segurança para abordar questões relativas à saúde mental e passam a conhecer melhor e a valorizar o contexto de vida dos usuários.

O estudo de Filha et al. (2009) aponta a aprendizagem de estratégias de promoção de saúde mental e de prevenção de transtornos decorrente da participação em grupos de TC. Para os autores, tal prática tem facilitado o trabalho dos profissionais da equipe de saúde da família no sentido de melhorar seu relacionamento com a comunidade e entender suas necessidades. Também Soares (2008) afirma que a TC confere, aos profissionais, compreensão e paciência para lidarem com as demandas de saúde mental.

Consideravelmente frequente é, também, o fomento às redes sociais que a TC promove. A leitura que os profissionais fazem da realidade em que estão inseridos e do atual modo de vida é que as pessoas estão muito solitárias, sem vínculos comunitários e, muitas vezes, sem vínculos familiares. $O$ grupo de TC é uma oportunidade de resgatar vínculos interpessoais e de se sentir mais integrado à comunidade, conforme aponta um dos sujeitos desse estudo:
"[...] a globalização desmancha isso, o comunitário. Ela desmancha a convivência das pessoas e tudo aquilo que existiu durante muito tempo, que é o apoio mútuo, de um bairro, de uma comunidade, com a aceleração vivida nos últimos 30, 40 anos, esses vínculos comunitários se explodem. Então a necessidade de alguma coisa que possa trazer novamente. E isso é bastante congruente com a Reforma, porque se você tira lá do hospital você vai mandar para onde, só para a família? Porque às vezes a família é uma pessoa só, é uma mãe com 5 filhos. Quer dizer, todo o tema da territorialização, novamente, porque a tendência atual, do capitalismo mais corporativista é desterritorializar total. A pessoa mora lá, trabalha não sei onde, mora num prédio e não conhece o vizinho. Isso foi muito bom para as pessoas nos grupos. Elas gostavam bastante do grupo". (Sujeito 05)

O fortalecimento das redes de apoio familiar e social, a melhoria dos vínculos familiares e comunitários e das redes de apoio e solidariedade são resultados comuns a outros estudos já realizados sobre a TC (Andrade et al., 2010; Silva, 2010; Filha et al., 2009; Guimarães, Valla, 2009; Guimarães, 2006; Holanda, 2006). A proximidade com redes familiares e sociais dos pacientes e a construção de vínculos duradouros com os usuários contribuem para a eficácia das intervenções clínicas, possibilitando a construção de uma clínica ampliada, que alcança aspectos subjetivos e sociais de cada sujeito e respeita a singularidade de cada caso (Campos, 2005).

Além disso, o conceito de território aplica-se à questão manicomial. Territorializar é uma proposta central para transformar, efetivamente, a realidade manicomial, propiciando condições para que os indivíduos possam estabelecer relações de troca. A partir do paradigma da desinstitucionalização, a 
participação da comunidade passa a ser fundamental para a ação de saúde mental, oferecendo uma infinidade de recursos e de possibilidades para os sujeitos (Mota, 2007).

O empoderamento dos integrantes da TC parece estar relacionado com a horizontalidade das relações, configurando um grupo que se constrói, se gerencia, se corresponsabiliza pelas mudanças que precisam ser operadas e que valoriza as contribuições de cada pessoa. As pessoas são valorizadas por sua experiência de vida, o que faz com que a identidade predominante no grupo não seja a de doente, como manifesta um dos profissionais entrevistados:

\footnotetext{
“Então as pessoas já não vêm por conta disso, às vezes mesmo tendo a acessibilidade não acessa o serviço porque não se reconhece como doente [...] E na TC, mesmo acontecendo no posto mas eles vinham lá para conversar com os amigos, conversar sobre algum outro tema, de um outro sofrimento. Esse ponto foi muito interessante. Então é mais ou menos isso que eu atribuo, um outro tipo de laço distinto do que um conteúdo programático educacional da unidade de saúde". (Sujeito 20)
}

É possível entender o empoderamento descrito pelos profissionais participantes desse estudo como um empoderamento psicológico, tal como explicitado por Carvalho (2004), como um sentimento de maior controle sobre a própria vida que os indivíduos experimentam através do pertencimento a distintos grupos, e que pode ocorrer sem que participem de ações políticas coletivas. Derivam do empoderamento psicológico (Carvalho, Gastaldo, 2008) estratégias de promoção que buscam fortalecer a autoestima e a capacidade de adaptação ao meio, e que procuram desenvolver mecanismos de autoajuda e de solidariedade.

Essas estratégias de promoção se assemelham aos benefícios advindos dos encontros de TC, cuja proposta, segundo Camargo (2005), parte do entendimento de que indivíduos e grupos sociais dispõem de mecanismos próprios para superarem as adversidades contextuais.

O princípio da horizontalidade também promove acolhimento, pois todos têm a capacidade de ajudar, de ensinar e de aprender, gerando um sentimento de igualdade que estimula a participação. Como o terapeuta comunitário não tem a função de transmitir conhecimento, ele se coloca numa relação de igualdade com os demais integrantes do grupo, preocupando-se apenas em conduzir algumas etapas metodológicas para que o grupo siga um formato. Esse lugar ocupado pelos profissionais de saúde promove uma atenção humanizada, que se contrapõe a um olhar técnico.

Para Tesser, Poli Neto e Campos (2010), o acolhimento busca ampliar a clínica e incluir outras abordagens e explicações além das biomédicas para os adoecimentos e demandas. Para garantir a resolubilidade dos problemas de forma multidisciplinar e intersetorial, no entanto, a habilidade clínica não é prescindível, deve estar atrelada ao trabalho em equipe, à construção de projetos terapêuticos e de avaliações de riscos/vulnerabilidades individuais e coletivas, que considerem elementos da vida familiar e social, o que permite concluir que a TC deve somar-se a outros dispositivos para que, realmente, possa acolher as demandas de saúde da população.

Para finalizar, outro benefício da TC é a congruência com a realidade do SUS, já que pode ser aplicada em diversos contextos, com um objetivo focado e brevemente atingido e requerendo poucos recursos para a sua implantação. Além disso, permite trabalhar algumas demandas sem necessidade de encaminhamento a profissionais especializados.

\section{Considerações finais}

Tendo como um de seus eixos teóricos o pensamento de Paulo Freire e pautada pelo preceito de horizontalidade das relações grupais, a TC pode contribuir para a redefinição da prática médica, através da valorização dos saberes e práticas dos sujeitos usualmente desconsiderados devido à sua origem popular. Essa metodologia de trabalho com grupos possibilita aos profissionais problematizarem vivências, compartilharem iniciativas de enfrentamento e buscarem entendimento das raízes das 
questões sociais, aproximando-se essa atuação diferenciada do enfoque transdisciplinar, caracterizado pela valorização das qualidades pessoais, valores, tradições culturais, emoções, conhecimentos, treino e experiência de vida, como atributos valiosos para o funcionamento do grupo.

O fortalecimento das redes de apoio familiar e social e a melhoria dos vínculos familiares e comunitários são benefícios decorrentes dos encontros de TC que podem contribuir para a construção de uma clínica ampliada e para a valorização dos recursos do território. Além disso, o princípio da horizontalidade promove acolhimento, atenção humanizada e empoderamento dos integrantes da TC, configurando um grupo que se constrói, se gerencia, se corresponsabiliza para com as mudanças que precisam ser operadas.

No entanto, as dificuldades enfrentadas para inserir essa tecnologia de cuidado no cotidiano dos serviços de saúde evidenciam a desvalorização das ações educativas, ficando tais práticas, muitas vezes, delegadas ao interesse individual daqueles que persistem com esses grupos, e que sozinhos dificilmente conseguem estimular a autonomia e a conscientização das comunidades. Daí a necessidade de que a atuação do terapeuta comunitário seja estendida a uma equipe multidisciplinar, dialogue com outros dispositivos, receba o apoio das gestões dos serviços e se alie a outras políticas públicas, ampliando seu campo de ação da saúde para outros setores.

A existência de pouco material bibliográfico e poucas pesquisas publicadas sobre a TC coloca-se como fragilidade neste estudo. Para amenizar tal dificuldade, foi realizada uma revisão minuciosa em bases de dados da área da saúde.

\section{Colaboradores}

Os autores Cristina dos Santos Padilha e Walter Ferreira de Oliveira participaram, igualmente, da elaboração do artigo, de sua discussão e redação, e da revisão do texto.

\section{Referências}

ALBUQUERQUE, P.C.; STOTZ, E.N. A educação popular na atenção básica à saúde no município: em busca da integralidade. Interface - Comunic., Saude, Educ., v.8, n.15, p.259-74, 2004.

ANDRADE, F.B. et al. Promoção da saúde mental do idoso na atenção básica: as contribuições da terapia comunitária. Texto Contexto Enferm., v.9, n.1, p.129-36, 2010.

ANDRADE, L.O.M. et al. O SUS e a Terapia Comunitária. Fortaleza: UFC, 2009.

BARDIN, L. Análise de conteúdo. Lisboa: Edições 70, 1977.

BRASIL. Ministério da Saúde. Humaniza SUS: documento base para gestores e trabalhadores do SUS. 4.ed. Brasília: MS, 2008. $2006 a$ Ministério da Saúde. Política Nacional de Promoção da Saúde. Brasília: MS, Ministério da Saúde. Política Nacional de Atenção Básica. Brasília: MS, 2006b.

. Ministério da Saúde. Portaria n. ${ }^{\circ}$ 971, de 03 de maio de 2006. Aprova a Política Nacional de Práticas Integrativas e Complementares (PNPIC) no Sistema Único de Saúde. Brasília: MS, 2006c.

BUSS, P.M. Uma introdução ao conceito de promoção da saúde. In: CZERESNIA, D.; FREITAS, C.M. (Orgs.). Promoção da saúde: conceitos, reflexões, tendências. Rio de Janeiro: Editora Fiocruz, 2003. p.11-32. 
CAMARGO, A.C. Tempo de falar e tempo de escutar: a produção de sentido em um grupo terapêutico. 2005. Dissertação (Mestrado) - Programa de Pós-Graduação em Psicologia, Universidade São Marcos, São Paulo. 2005. Disponível em: <http:// www.abratecom.org.br/publicacoes/academicos/pdf/Dissertacao_Amilton.pdf>. Acesso em: 13 maio 2009.

CAMPOS, G.W.S. El filo de la navaja de la función filtro: reflexiones sobre la función clínica en el Sistema Único de Salud en Brasil. Rev. Bras. Epidemiol., v.8, n.4, p.477-83, 2005.

CARVALHO, S.R. Os múltiplos sentidos da categoria "empowerment" no projeto de Promoção à Saúde. Cad. Saude Publica, v.20, n.4, p.1088-95, 2004.

CARVALHO, S.R.; GASTALDO, D. Promoção à saúde e empoderamento: uma reflexão a partir das perspectivas crítico-social e pós-estruturalista. Cienc. Saude Colet., v.13, supl.2, p.2019-40, 2008. Disponível em: <http://www.scielo.br/pdf/csc/v13s2/ v13s2a07.pdf $>$. Acesso em: 14 maio 2011.

FILHA, M.O.F.; CARVALHO, M.A.P. A Terapia Comunitária em um Centro de Atenção Psicossocial: (des)atando pontos relevantes. Rev. Gaucha Enferm., v.31, n.2, p.232-9, 2010.

FILHA, M.O.F. et al. A Terapia Comunitária como estratégia de promoção à saúde mental: o caminho para o empoderamento. Rev. Eletr. Enferm., v.11, n.4, p.964-70, 2009

FUKUI, L.; MARCHETTI, L.B. Terapia Comunitária: uma forma de atuação no espaço público. In: CONGRESSO BRASILEIRO DE TERAPIA COMUNITÁRIA, 2., 2004, Brasília. Anais... Brasília, 2004. Disponível em: <http://www.usp.br/nemge/ textos_tecendo_estudando/terapiacomun_espacopublico_fukui.pdf $>$. Acesso em: 1 maio 2010

GOMES, L.B.; MERHY, E.E. Compreendendo a Educação Popular em Saúde: um estudo na literatura brasileira. Cad. Saude Publica, v.27, n.1, p.7-18, 2011

GUIMARÃES, F.J. Repercussões da Terapia Comunitária no cotidiano de seus participantes. 2006. Dissertação (Mestrado) - Programa de Pós-Graduação em Enfermagem, Universidade Federal da Paraíba, João Pessoa. 2006. Disponível em: <http://abratecom.org.br/publicacoes/academicos/pdf/DISSERTACAOFINAL.pdf>. Acesso em: 1 maio 2009.

GUIMARÃES, M.B.L.; VALLA, V.V. Terapia Comunitária como expressão de educação popular: um olhar a partir dos encontros com agentes comunitários de saúde. In: REUNIÃO ANUAL DA ANPED, 32., 2009, Caxambú. Anais... Caxambu, 2009. Disponível em: <http://www.anped.org.br/reunioes/32ra/arquivos/trabalhos/ GT06-5115-Res.pdf>. Acesso em: 1 maio 2010.

HOLANDA, V.R. A contribuição da Terapia Comunitária para o enfrentamento das inquietações das gestantes. 2006. Dissertação (Mestrado) - Programa de PósGraduação em Enfermagem, Universidade Federal da Paraíba, João Pessoa. 2006. Disponível em: <http://www.abratecom.org.br/publicacoes/academicos/pdf/ Viviane_Rolim_de_Holanda_-_Dissertacao.pdf>. Acesso em: 10 abr. 2009.

LOPES, M.J. A transdisciplinaridade em saúde. In: LOPES, M.; MENDES, F; MOREIRA, A. (Orgs.). Exercícios de diálogo e convergência. Coimbra: Formasau, 2009. p.55-67.

LUISI, L.V.V. Terapia Comunitária: bases teóricas e resultados práticos de sua aplicação. 2006. Dissertação (Mestrado) - Programa de Estudos Pós-Graduados em Psicologia Clínica, Pontifícia Universidade Católica de São Paulo, São Paulo. 2006. Disponível em: $<$ http://www.sapientia.pucsp.br/tde_busca/arquivo.php?codArquivo $=3161>$. Acesso em: 14 mar. 2010 
MACHADO, D.M. A desconstrução do manicômio interno como determinante para a inclusão social. 2006. Dissertação (Mestrado) - Programa de Pós-Graduação em Ciências da Saúde, Universidade de Brasília, Brasília. 2006. Disponível em: < http:// bdtd.bce.unb.br/tedesimplificado/tde_arquivos/6/TDE-2006-11-22T131240Z-457/ Publico/Dissert_final.pdf>. Acesso em: 14 mar. 2010.

MENDES, F. As vulnerabilidades da Educação para a Saúde. In: LOPES, M.; MENDES, F.; MOREIRA, A. (Orgs.). Exercícios de diálogo e convergência. Coimbra: Formasau, 2009. p.55-67.

MOTA, T.D. As necessidades de saúde da perspectiva dos usuários de um serviço comunitário de saúde mental. 2007. Dissertação (Mestrado) - Programa de PósGraduação em Enfermagem, Universidade de São Paulo, São Paulo. 2007. Disponível em: <http://www.teses.usp.br/teses/disponiveis/7/7134/tde-20042007-101132/>. Acesso em: 13 maio 2009.

OLIVEIRA, D.C. Análise de conteúdo temático-categorial: uma proposta de sistematização. Rev. Enferm. UERJ, v.16, n.4, p.569-76, 2008.

OMS - Organização Mundial da Saúde. Estrategia de la OMS sobre medicina tradicional 2002-2005. Ginebra: OMS, 2002.

ROCHA, I.A. et al. A Terapia Comunitária como um novo instrumento de cuidado para a saúde mental do idoso. Rev. Bras. Enferm. REBEn, v.62, n.5, p.687-94, 2009.

SILVA, A.L.C. Terapia comunitária como abordagem complementar no tratamento da depressão: uma estratégia de Saúde Mental no PSF de Petrópolis/RJ. 2010. Dissertação (Mestrado) - Programa de Pós-Graduação em Saúde da Família, Universidade Estácio de Sá, Rio de Janeiro. 2010. Disponível em: <http://portal.estacio.br/media/ 1958495/ana\%20lucia\%20dissertação.pdf>. Acesso em: 14 maio 2011.

SOARES, C.S.D.A. Terapia Comunitária na Estratégia de Saúde da Família: implicações no modo de andar a vida dos usuários. 2008. Dissertação (Mestrado) - Programa de Pós-Graduação em Enfermagem Psiquiátrica, Universidade de São Paulo, Ribeirão Preto. 2008. Disponível em: <http://www.teses.usp.br/teses/disponiveis/22/22131/ tde-12012009-160828/>. Acesso em: 6 maio 2009.

TESSER, C.D.; POLI NETO, P.; CAMPOS, G.W.S. Acolhimento e (des)medicalização social: um desafio para as equipes de saúde da família. Cienc. Saude Colet., v.15, supl.3, p.3615-24, 2010.

VASCONCELOS, E.M. Educação popular: de uma prática alternativa a uma estratégia de gestão participativa das políticas de saúde. Physis, v.14, n.1, p.67-83, 2004.

VICTOR, J. F. et al. Grupo Feliz Idade: cuidado de enfermagem para a promoção da saúde na terceira idade. Rev. Esc. Enferm. USP, v.41, n.4, p.724-30, 2007. 
PADILHA, C.S.; OLIVEIRA, W.F. Terapia comunitaria: práctica relatada por los profesionales del SUS de Santa Catarina, Brasil. Interface - Comunic., Saude, Educ., v.16, n.43, p.1069-83, out./dez. 2012.

El objetivo de este estudio, de naturaleza exploratoria y descriptiva, es describir las prácticas de la Terapia comunitaria relatadas por 27 profesionales de la red del Sistema Único de Salud (SUS) de Santa Catarina, Brasil. La recolección de datos utilizó la entrevista individual semi-dirigida y empleó el análisis de contenido categorial temático. Los resultados fueron agrupados en cinco categorías: Prácticas de terapia comunitaria; estrategias de implantación; dificultades; elementos facilitadores; y beneficios. Se concluye que la Terapia comunitaria puede contribuir con la construcción de una clínica ampliada y la valorización de los recursos del territorio. Sin embargo, es necesario que la actuación del terapeuta comunitario sea extendida a un equipo multidisciplinario, dialogue con otros dispositivos, reciba el apoyo de las gestiones de los servicios y haga alianzas con otras políticas públicas, ampliando su campo de acción para otros sectores.

Palabras clave: Terapia comunitaria. SUS. Profesionales de salud. Prácticas de salud. Intervención psico-social. 
be[m] Samsara Urbe[m] Samsara Urbe[m] Urbe[m] Samsara Urbe[m] Sam sara urbe[m] Samsara Urbe[m] Samsara 